Hydrol. Earth Syst. Sci., 16, 4009-4022, 2012

www.hydrol-earth-syst-sci.net/16/4009/2012/

doi:10.5194/hess-16-4009-2012

(C) Author(s) 2012. CC Attribution 3.0 License.

\title{
Multi-offset ground-penetrating radar imaging of a lab-scale infiltration test
}

\author{
A. R. Mangel ${ }^{1}$, S. M. J. Moysey ${ }^{1}$, J. C. Ryan ${ }^{1}$, and J. A. Tarbutton ${ }^{2}$ \\ ${ }^{1}$ Environmental Engineering and Earth Sciences, Clemson University, 340 Brackett Hall, Clemson, SC 29634, USA \\ ${ }^{2}$ Mechanical Engineering, Clemson University, 102 Fluor Daniel Building, Clemson, SC 29634, USA
}

Correspondence to: A. R. Mangel (amangel@clemson.edu)

Received: 31 October 2011 - Published in Hydrol. Earth Syst. Sci. Discuss.: 15 November 2011

Revised: 6 September 2012 - Accepted: 2 October 2012 - Published: 5 November 2012

\begin{abstract}
A lab scale infiltration experiment was conducted in a sand tank to evaluate the use of time-lapse multi-offset ground-penetrating radar (GPR) data for monitoring dynamic hydrologic events in the vadose zone. Sets of 21 GPR traces at offsets between $0.44-0.9 \mathrm{~m}$ were recorded every $30 \mathrm{~s}$ during a $3 \mathrm{~h}$ infiltration experiment to produce a data cube that can be viewed as multi-offset gathers at unique times or common offset images, tracking changes in arrivals through time. Specifically, we investigated whether this data can be used to estimate changes in average soil water content during wetting and drying and to track the migration of the wetting front during an infiltration event. For the first problem we found that normal-moveout (NMO) analysis of the GPR reflection from the bottom of the sand layer provided water content estimates ranging between $0.10-0.30$ volumetric water content, which underestimated the value determined by depth averaging a vertical array of six moisture probes by $0.03-0.05$ volumetric water content. Relative errors in the estimated depth to the bottom of the $0.6 \mathrm{~m}$ thick sand layer were typically on the order of $2 \%$, though increased as high as $25 \%$ as the wetting front approached the bottom of the tank. NMO analysis of the wetting front reflection during the infiltration event generally underestimated the depth of the front with discrepancies between GPR and moisture probe estimates approaching $0.15 \mathrm{~m}$. The analysis also resulted in underestimates of water content in the wetted zone on the order of 0.06 volumetric water content and a wetting front velocity equal to about half the rate inferred from the probe measurements. In a parallel modeling effort we found that HYDRUS-1D also underestimates the observed average tank water content determined from the probes by approximately 0.01-0.03 volumetric water content, despite the fact that the
\end{abstract}

model was calibrated to the probe data. This error suggests that the assumed conceptual model of laterally uniform, onedimensional vertical flow in a homogenous material may not be fully appropriate for the experiment. Full-waveform modeling and subsequent NMO analysis of the simulated GPR response resulted in water content errors on the order of $0.01-$ 0.03 volumetric water content, which are roughly $30-50 \%$ of the discrepancy between GPR and probe results observed in the experiment. The model shows that interference between wave arrivals affects data interpretation and the estimation of traveltimes. This is an important source of error in the NMO analysis, but it does not fully account for the discrepancies between GPR and the moisture probes observed in the experiment. The remaining discrepancy may be related to conceptual errors underlying the GPR analysis, such as the assumption of uniform one-dimensional flow, a lack of a sharply defined wetting front in the experiment, and errors in the petrophysical model used to convert dielectric constant to water content.

\section{Introduction}

Ground-penetrating radar (GPR) has been established as a valuable tool for evaluating soil water content (Huisman et al., 2003). Surface-based radar reflection surveys are particularly appealing for this purpose as they can map large-scale regions that are relevant to field applications ranging from precision agriculture (Freeland et al., 1998; Lunt et al., 2005) to contaminant transport (Brewster et al., 1995). Several authors, including Lunt et al. (2005) and Grote et al. (2005), have shown that GPR reflection surveys can provide water 
content estimates with an accuracy comparable to traditional invasive, spatially limited methods, e.g., time-domain reflectometry (TDR) or neutron probes. A significant advantage of these probes over radar, however, is that they can provide reliable water content estimates with high temporal resolution, e.g., at time scales capturing the dynamics of individual infiltration events. In contrast, almost all studies using GPR to quantitatively estimate water content have been performed under nearly steady-state hydraulic conditions or where changes in water content have been observed over long periods of time, e.g., seasonally, due to the significant effort and time required for data collection (Lunt et al., 2005; Grote et al., 2005; Steelman and Endres, 2010)

Most common methods for estimating water content from GPR are based on deriving wave velocity from arrivals identified in radar images (Huisman et al., 2003). For example, Lunt et al. (2005) mapped seasonal changes in water content over an $80 \mathrm{~m} \times 180 \mathrm{~m}$ area of a vineyard by evaluating variations in wave velocity determined from the traveltime of reflections produced by a clay layer of known depth, where the depth of the clay layer was inferred from borehole data. Water contents were then estimated from the velocities using a site-specific petrophysical equation. Following a different approach, Huisman et al. (2001) used changes in the traveltime of the direct groundwave in a wide angle reflection-refraction (WARR) survey to calculate lateral variations in wave velocity, which were subsequently transformed to near surface water content. While analysis of the groundwave has been shown to yield excellent results when the soil near the ground surface is approximately homogeneous, it is not clear whether accurate wave velocities can be obtained during an infiltration event. In this case, energy can be trapped in the low-velocity waveguide behind the wetting front, causing dispersion of the groundwave (van der Kruk, 2006). In contrast, van Overmeeren et al. (1997) analyzed groundwave, reflected and refracted wave arrivals in multioffset data obtained from central midpoint (CMP) surveys to successfully determine both lateral and vertical variations in water content.

Traditional multi-offset GPR survey techniques, i.e., CMP or WARR, are appealing strategies for monitoring water content changes associated with one-dimensional infiltration as they are well established in the literature (Berard and Maillol, 2007; Fisher et al., 1992; Greaves et al., 1996; Grote et al., 2005 ) and can be easily put into practice with widely available commercial GPR systems. Analysis of the data from these surveys typically relies on normal-moveout (NMO) corrections (Fisher et al., 1992), however, which assumes idealized, locally continuous reflector geometries. To overcome these limitations, Bradford (2008) used reflection tomography to obtain improved velocity estimates and GPR reflection images in areas with significant lateral heterogeneity. The intensive surveying required to collect data for reflection tomography, however, makes the approach challenging to implement at the short time scales associated with the dynamics of individual soil hydrologic events, such as infiltration in response to rainfall. Given that natural infiltration in soils is often conceptualized as a one-dimensional process at field scales, it is not yet clear whether meaningful dynamic water content estimates can be obtained from multi-offset GPR using a NMO approach or whether more data intensive reflection tomography methods will need to be adopted.

There are relatively few examples in the literature that directly illustrate the influence of soil hydrology on surfacebased GPR surveys (Freeland et al., 2006; Grasmueck et al., 2010; Grote et al., 2005; Haarder et al., 2011; Lambot et al., 2008; Moysey, 2010; Saintenoy et al., 2008; Truss et al., 2007). Truss et al. (2007) performed 3-D time-lapse GPR imaging of infiltration in an oolitic limestone that revealed macroscopic funnel flow effects. These authors also observed overall shifts in reflector traveltimes that they suggested were caused by changes in soil moisture, but they did not provide direct estimates of water content. Haarder et al. (2011) used constant-offset GPR surveys to monitor an infiltration experiment where dye was applied to mark preferential flow paths that were later identified when the site was excavated following the test. These authors concluded that wetting front nonuniformity and fingering complicated the GPR images, noting impacts on both radar velocity and amplitudes, but preferential flow features themselves were not resolved. Grote et al. (2005) used constant-offset and CMP surveys to monitor changes in water content beneath a synthetic road bed during infiltration tests conducted over a period of approximately 35 weeks and found close agreement with gravimetric water content estimates. Moysey (2010) used a pair of fixed antennas placed on the surface of a sand tank to show that changes in water content during wetting and drying events produce distinct arrival trajectories in transient constant offset GPR data. These data were then used to calibrate the parameters of a soil infiltration model. Because the antennas were maintained at a constant offset from each other in that work, however, it was not possible to directly determine subsurface velocity or estimate reflector depths using the GPR data alone. Despite the various hydrologic and geophysical insights provided by these studies, none has directly evaluated whether multi-offset imaging can be used to quantify water content changes in a dynamically changing soil environment at timescales typical of rainfall and irrigation events.

In this study we investigate whether NMO analysis of WARR surveys can be used to continuously monitor water content, track infiltration fronts, and image soil structure over the course of a short-term infiltration experiment. The experiment is conducted in a sand tank where water is applied uniformly to the surface while an automated positioning system moves a receiver antenna to 21 different positions above the tank. This unique approach to antenna positioning allows us to collect multi-offset images as approximate "snapshots" of the tank over time. Conceptualizing the data as a 3-D volume, i.e., with dimensions of GPR traveltime, antenna offset, and elapsed time since the start of the experiment, provides 
a rich space for enhanced analysis of transient processes that we expect will allow us to achieve reliable, high resolution monitoring of hydrologic events in soils.

\section{Methods}

\subsection{Experimental procedures}

The infiltration experiment was conducted in a $150 \mathrm{~cm}$ $\times 150 \mathrm{~cm} \times 80 \mathrm{~cm}(\mathrm{~L} \times \mathrm{W} \times \mathrm{H})$ wooden tank illustrated in Fig. 1. Drains at the base of the tank were left open at all times to allow for free discharge of effluent. The tank was packed with a $60 \mathrm{~cm}$ layer of homogeneous, medium grained $(0.25-0.5 \mathrm{~mm})$ sand, below which was placed a $20 \mathrm{~cm}$ layer of gravel to allow for drainage. The sand was packed into the tank in roughly $1 \mathrm{~cm}$ increments. While packing the sand, fifteen Decagon EC-5 soil moisture probes were installed in the tank. The probes were placed in a central array at depths of $5,10,15,25,35,45$ and $55 \mathrm{~cm}$ and four lateral arrays, each with probes at depths of 15 and $45 \mathrm{~cm}$. The probes were calibrated for the sand prior to packing and provided water content measurements at $10 \mathrm{~s}$ intervals throughout the experiment. The depth distribution of initial water content prior to the experiment was evaluated using the probes and found to be at approximate capillary equilibrium assuming no vertical flow; the water content was non-uniform due to redistribution of water during previous infiltration tests conducted in the tank (see Fig. 2).

The infiltration event was initiated by applying water to the sand surface using an irrigation grid consisting of a network of parallel $(0.64 \mathrm{~cm}$ O.D. $\times 0.43 \mathrm{~cm}$ I.D.) polyethylene tubes. The tubes were spaced at $1 \mathrm{~cm}$ intervals and punctured every $1 \mathrm{~cm}$ to give a $1 \mathrm{~cm} \times 1 \mathrm{~cm}$ grid of irrigation points over the central portion of the tank $(\sim 130 \mathrm{~cm} \times 75 \mathrm{~cm})$ where the GPR data were collected. A peristaltic pump monitored by a flow meter provided control over the flux of water applied to the tank. The tubing was initially purged of air using a set of valves so that water could be applied uniformly to the surface of the tank as soon as the pump was turned on.

An automated radar imaging system was developed using LabVIEW (National Instruments, Austin, Texas) to achieve fast and accurate multi-offset antenna positioning for the WARR surveys performed during the experiment. A stationary transmitter antenna was placed on the irrigation grid $7 \mathrm{~cm}$ from one end of the tank while the receiver antenna was mounted $4 \mathrm{~cm}$ above the sand surface on a carriage that could move the length of the tank on an elevated track (Fig. 1). The receiver antenna was moved using a belt drive (Pittman Express DC servo motor, Model GM9236S021-R1 and Pololu motor drive chip, Model MD01B), which had a 500 pulse per revolution encoder on the motor to provide lateral positioning precision on the order of tenths of a millimeter. LabVIEW was interfaced with the GPR trigger to fire the transmitter whenever the receiver antenna was stopped at a desired

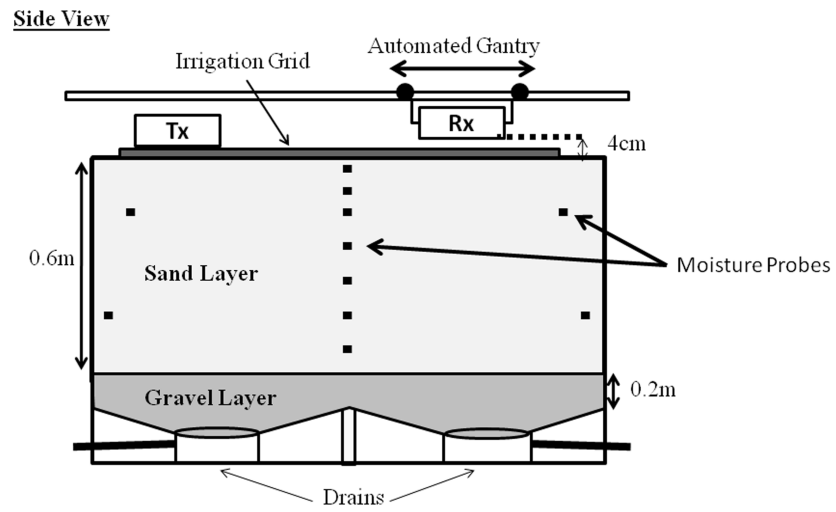

Fig. 1. Experimental setup for lab-scale infiltration experiments.

survey position, though the radar's standard control software was run from a separate computer to collect the data.

The radar system used in the experiment was a PulseEKKO 1000 with $900 \mathrm{MHz}$ antennas (Sensors and Software, Mississauga, Ontario, Canada). The transmitter antenna was fired as the receiver was scanned across the tank at 21 different positions with antenna offsets ranging from $0.44-0.9 \mathrm{~m}$. Each round trip of the receiver antenna across the tank was completed in approximately $60 \mathrm{~s}$, but data were collected in both directions so a complete 21 trace WARR survey was collected every $30 \mathrm{~s}$ during the experiment.

No water was applied to the tank for the first $8 \mathrm{~min}$ of the experiment to ensure that consistent GPR data could be obtained and to assess background conditions in the sand. Water was then applied at the surface of the tank by the irrigation grid for $65 \mathrm{~min}$ at a rate of $0.44 \mathrm{~cm} \mathrm{~min}^{-1}$; this rate was selected to provide a strong contrast in water content within the tank across the wetting front. After this time, the pump was turned off and an additional 107 min of recovery data were collected as water redistributed in the tank. A total of 6300 GPR traces were collected as 300 multi-offset WARR surveys during the experiment.

\subsection{Normal-moveout analysis of WARR surveys}

Multi-offset GPR data are typically analyzed by applying normal-moveout (NMO) corrections to determine the onedimensional velocity structure of the subsurface, e.g., see Yilmaz (1987) for details on NMO analysis and Fisher et al. (1992) for application of NMO to GPR. Using the NMO approach, the apparent (root mean square) velocity ( $\left.V_{\mathrm{RMS}}\right)$ of a wave traveling through the subsurface can be determined by assuming that the traveltime of a wave reflected from a subsurface interface increases in a well-defined way as the offset between transmitter and receiver antennas is increased. For a horizontal interface, the relationship between the two-way traveltime $(t)$ to a reflector located at depth $(z)$ and antenna offset $(x)$ is linear when plotted as $x^{2}$ vs. $t^{2}$ : 
a)

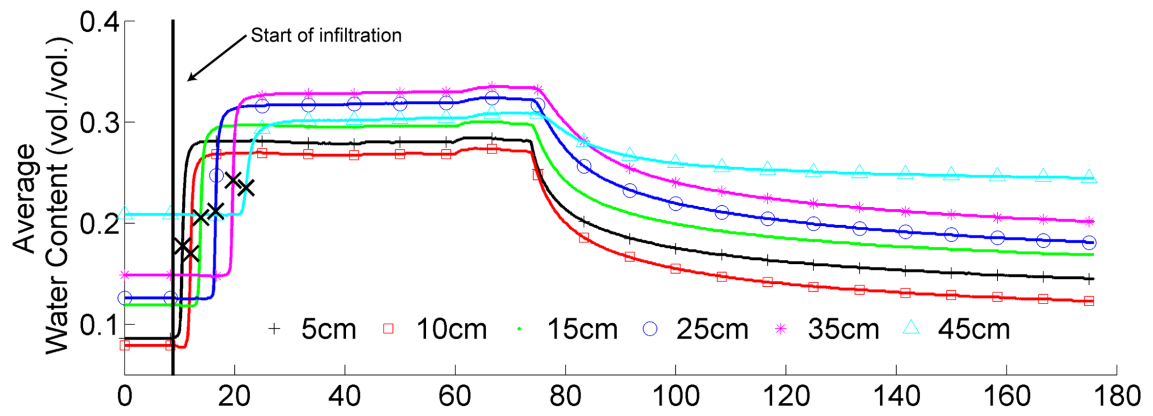

b)

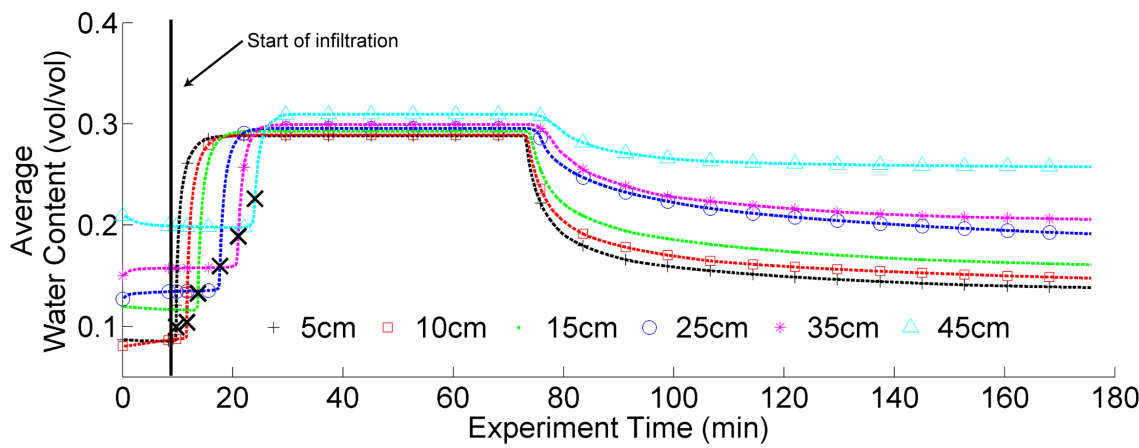

Fig. 2. (a) Data from soil moisture probes located in the central array of the sand tank and (b) HYDRUS-1D model results. "X" marks indicate wetting front picks from taking the maximum of first derivative of the series in time.

$t^{2}=\frac{x^{2}}{V_{\mathrm{RMS}}^{2}}+\frac{4 z^{2}}{V_{\mathrm{RMS}}^{2}}$

The first step in NMO analysis of WARR data is therefore to identify a coherent set of arrivals in a multi-offset image that represents the reflection response from a subsurface interface. The traveltimes of the reflected wave estimated at each different offset between the transmitter and receiver antennas can then be fit by Eq. (1), with the resulting slope and intercept of the best fit line yielding $V_{\mathrm{RMS}}$ and the depth $(z)$ of the reflector, respectively. Due to the mode of data collection used in this study, identification of coherent reflections can also be aided by reflection patterns that are apparent when the data are plotted as constant-offset gathers, as illustrated by Moysey (2010). We emphasize, however, that the ability to constrain both subsurface velocity and reflector depth over time is a key advantage of multi-offset versus constant-offset GPR data.

The effective dielectric constant $(\kappa)$ of the subsurface can be determined from velocity using Eq. (2), where $c$ is the speed of light in a vacuum. The dielectric constant can then be used to determine the average water content $(\theta)$ of the subsurface using a petrophysical relationship such as the Topp equation (Topp et al., 1980), which is given in Eq. (3). For an in depth review and description of current GPR theory and applications, refer to Jol et al. (2009).

$$
\begin{aligned}
& \kappa=\left(\frac{c}{V_{\mathrm{RMS}}}\right)^{2} \\
& \theta=-0.053+0.029 \kappa-5.5 \times 10^{-4} \kappa^{2}+4.3 \times 10^{-6} \kappa^{3}
\end{aligned}
$$

\subsection{Numerical modeling}

Numerical modeling of the infiltration experiment and GPR response was performed to improve the interpretation of the experimental results and identify possible sources of error. The homogeneous $0.60 \mathrm{~m}$ profile of sand was discretized into 1001 equally-sized cells $\left(6 \times 10^{-4} \mathrm{~m}\right)$ within HYDRUS1D (Simunek et al., 2005). Non-uniform initial soil moisture conditions were specified for the model based on the in-situ moisture probe readings observed at the beginning of the tank experiment (Fig. 2a). The same flux schedule used in the experiment was specified as the upper boundary condition in the model, and the bottom boundary was specified as a seepage face to capture the capillary barrier effect that occurs at the sand-gravel interface in the tank. Observation points were specified to represent soil moisture probe locations in the tank, whereas the full simulated depth profiles of water content were used for the GPR simulations. The Mualemvan Genuchten parameters of the soil (Mualem, 1976; van Genuchten, 1980) used in the simulations were determined by calibrating the model in HYDRUS-1D using the observed moisture probe data from the tank experiments. Starting parameters for the inversion were initialized using the measured 
Table 1. Sand hydraulic parameters used in HYDRUS-1D simulations. Lab core measurements were used as initial parameters in the HYDRUS-1D inversion.

\begin{tabular}{|c|c|c|c|c|c|}
\hline & $\begin{array}{c}\text { Residual } \\
\text { water } \\
\text { content } \\
\theta_{\mathrm{r}} \\
{\left[\mathrm{vol} \mathrm{vol}^{-1}\right]}\end{array}$ & $\begin{array}{c}\text { Saturated } \\
\text { water } \\
\text { content } \\
\theta_{\mathrm{s}} \\
{\left[\mathrm{vol} \mathrm{vol}^{-1}\right]}\end{array}$ & $\begin{array}{c}\begin{array}{c}\text { Air-entry } \\
\text { parameter }\end{array} \\
\alpha \\
{\left[\mathrm{cm}^{-1}\right]}\end{array}$ & $\begin{array}{c}\text { Shape } \\
\text { parameter } \\
\\
n \\
{[-]}\end{array}$ & $\begin{array}{c}\text { Saturated } \\
\text { hydraulic } \\
\text { conductivity } \\
K_{\mathrm{S}} \\
{\left[\mathrm{cm} \mathrm{min}{ }^{-1}\right]}\end{array}$ \\
\hline Lab cores* & 0.06 & 0.38 & 0.058 & 4.09 & 4.6 \\
\hline Calibrated & 0.04 & 0.35 & 0.045 & 2.10 & 2.8 \\
\hline
\end{tabular}

* Measured with constant head permeameter and hanging column.

lab-scale parameters listed in Table 1, while upper and lower limits for the parameters were set well out of the expected range.

GPR simulations were performed using the finite difference time domain code implemented by Irving and Knight (2006) in MATLAB to solve Maxwell's equations in two dimensions. A cross-section of the true tank geometry parallel to the axis of the WARR surveys was used for the simulations. To simulate the GPR response at any point during the experiment, the 1-D profile of water contents simulated by HYDRUS-1D was extrapolated to 2-D, i.e., assuming a laterally uniform wetting front, and used as input for the GPR forward model. In addition to the sand, a layer of air outside the tank was included to allow for reflected and refracted waves at these boundaries. Cell sizes for the entire model domain were set to $0.05 \mathrm{~m} \times 0.025 \mathrm{~m}$ (length $\times$ depth). Perfectly matched layer (PML) absorbing boundaries were specified around the model domain to eliminate additional spurious reflections. The dielectric permittivity of the sand within the tank was obtained using the Topp equation, Eq. (3), to transform the water content profile output from HYDRUS-1D. Electrical conductivity was set to constant values of $1 \mathrm{mS} \mathrm{m}^{-1}$ and $0 \mathrm{mS} \mathrm{m}^{-1}$ for the sand and air, respectively. The conductivity of the sand was chosen to be constant since we are focused here on the kinematics of wave migration, but we acknowledge that changes in saturation would also affect the amplitude of the waves. The magnetic permeability was set to a constant value of $1.256 \times 10^{-6} \mathrm{H} \mathrm{m}^{-1}$ (permittivity of free space) for the entire model domain. The source wavelet used in the simulations was the normalized first derivative of the BlackmanHarris window with a dominant frequency of $900 \mathrm{MHz}$. See Irving and Knight (2006) for additional model details.

\section{Results and discussion}

\subsection{Water content probes}

Volumetric water contents measured by the embedded central probe array are shown in Fig. 2a. Initial water contents in the tank generally increase with depth, except that the probe located at $0.10 \mathrm{~m}$ depth was $\sim 0.005 \mathrm{vol} \mathrm{vol}^{-1}$ drier than the probe at $0.05 \mathrm{~m}$ (Fig. 2a). The shallower probe responds first once infiltration begins, however, and the downward migration of the wetting front in Fig. 2a shows a sequential increase in water content at each of the deeper probes as the experiment progresses. All probes reached constant water contents near 0.30 volumetric water content about $30 \mathrm{~min}$ into the experiment, indicating that steady state flow has been achieved. At this time, the water content for probes at $25 \mathrm{~cm}$ and $35 \mathrm{~cm}$ is higher than the probe at $45 \mathrm{~cm}$; given that greater depths in the tank are expected to have higher water content due to capillary effects, this discrepancy could indicate some variability in the packing of the sand, error in the probe readings, or effects from non-uniform flow. After irrigation is stopped $73 \mathrm{~min}$ into the experiment, the probes indicate progressive drainage of the tank from top to bottom.

The time at which the initial increase in water content is observed at each probe can be used to infer the progression of the wetting front as in Fig. 3a. In cases where the change in water content across the front is diffuse, however, this initial change may be small and not provide a significant dielectric contrast capable of creating a strong GPR reflection compared to other parts of the wetting front. We therefore consider the time when the change in water content observed at a probe is most rapid, i.e., the temporal derivative is a maximum, as an alternate way of identifying the arrival of the wetting front that may be more comparable to the GPR results. If the wetting front is a sharp, well-defined interface, these two approaches for defining the front are approximately equal. If the wetting front is diffuse, however, the front defined using the maximum temporal derivative will arrive later than the front defined by the initial change in water content (e.g., Fig. 3).

Based on travel times obtained using the maximum temporal derivative of the probe data, the wetting front moves with an approximately constant velocity of $3.4 \mathrm{~cm} \mathrm{~min}^{-1}$ (Fig. 3a). This velocity is generally consistent with the applied flux of $0.44 \mathrm{~cm} \mathrm{~min}^{-1}$ when considering the fact that the unsaturated fraction of the sand controlling the wetting front velocity ranges between about $0.1-0.2$ volumetric water content (Fig. 2a). Furthermore, the wetting front appears 
a)

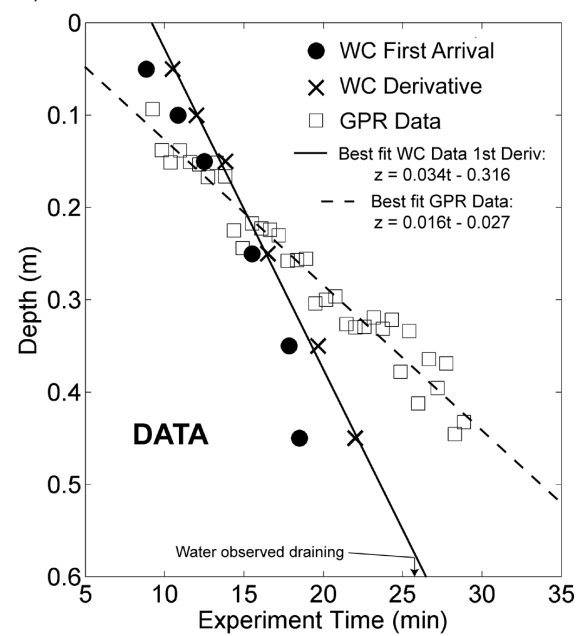

b)

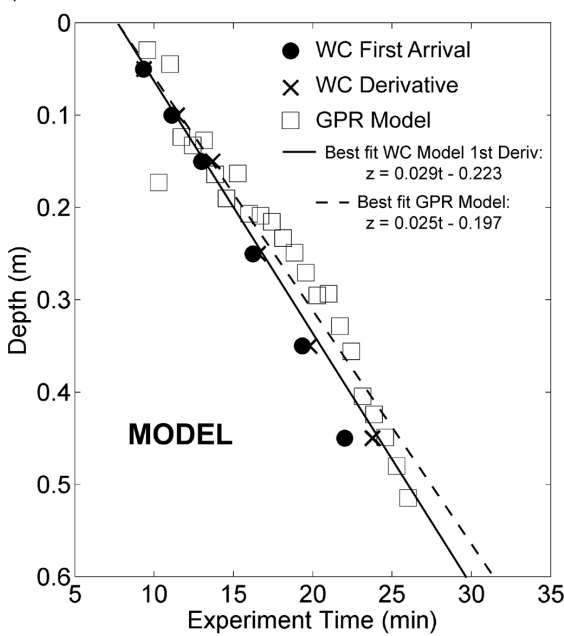

Fig. 3. Estimated depth to the wetting front based on water content probe and GPR measurements for (a) experimental and (b) simulated data. Arrival of the wetting front based on probe measurements was calculated using the first arrival of water and the maximum temporal derivative of the water content in the probe record. Water was observed draining from the tank at 26 min (indicated by the arrow).

to reach the bottom of the sand layer in the tank at approximately $27 \mathrm{~min}$ into the experiment (Fig. 3a), which is consistent with the time that water was observed to discharge from the tank drain 26 min into the experiment. Data from the lateral arrays of probes installed at depths of 15 and $45 \mathrm{~cm}$ (not shown) indicate that the migration of the wetting front was not uniform across the tank; at both depths the standard deviation of the front arrival time for the five probes in each array was $2.6 \mathrm{~min}$.

Apparent hydraulic parameters for the tank were estimated by calibrating the HYDRUS-1D model with a single homogeneous sand layer to the observed water content data given in Fig. 2a. The resulting parameter values from the calibration are given in Table 1. Figure 2 shows that the calibrated model is able to reproduce the moisture probe data fairly well $\left(R^{2}=0.93\right.$; $\mathrm{RMSE}=0.017$ volumetric water content $)$, though there are notable discrepancies. Prior to the start of the infiltration experiment, the model undergoes a brief period of redistribution allowing the initial water contents in the tank to re-equilibrate for the calibrated soil parameters. After the start of infiltration, all simulated observation nodes show a sequential increase in water content associated with the propagating wetting front (Fig. 2b). The wetting front (as interpreted using the temporal derivative) moves with an average velocity of $2.9 \mathrm{~cm} \mathrm{~min}^{-1}$ and reaches the bottom of the model domain around $28.5 \mathrm{~min}$, which is slightly slower and later than what was observed in the actual experiment (Fig. 3). All observation points reach a steady water content of around 0.3 volumetric water content approximately $30 \mathrm{~min}$ into the experiment (Fig. 2b). The model therefore fails to capture the variation in water content observed for the probe data during the steady-state portion of the infiltration experiment (Fig. 2a).
There is an overall good level of agreement between the water contents measured by the central probe array and those predicted by the calibrated model given that the expected accuracy of the probes is 0.02 (Decagon.com, 2012). The discrepancies between the observed and modeled water contents, however, appear to be systematic rather than random. The errors could therefore indicate that the assumed onedimensional conceptual model for flow through a homogenous soil may not be fully appropriate for this experiment. It is possible that heterogeneities could have been unintentionally produced when packing the sand as thin $(1 \mathrm{~cm})$ layers in the tank. Such layering could account for the observed vertical variability in the observed water content data (Fig. 2a), however, we were not able to find direct evidence for these zones from the GPR data. It is also possible that non-uniform flow could have occurred during the experiment, e.g., due to lateral migration or channeling of water induced by heterogeneity, but we also lack direct evidence of these phenomena.

Increasing the number of free parameters in the model by using more complex conceptualizations of the flow system, e.g., a layered model, allows the variability observed in the water content data to be captured $\left(R^{2}=0.98\right.$; fitting results are not shown). We do not feel that the increased complexity of the model is justified, however, given the magnitude of the error expected in the water content measurements and lack of supporting data for these alternate models. We therefore choose to accept the one-dimensional conceptualization as a gross description of the flow system that is consistent with the observed water content data. We acknowledge, however, that there may in fact be errors in this conceptual flow model that could affect the true GPR response and invalidate the assumption of a layered medium underlying the NMO analysis of the WARR surveys. Our goal in subsequent sections of this 
paper is therefore to use the simulations as a reference that provides a quantitative context for assessing the significance of discrepancies between the observed probe and GPR data. We do not use the observed GPR data to further refine the conceptual accuracy of the flow model.

\subsection{GPR arrivals}

Major arrivals that can be identified in both the empirical and simulated GPR data include the direct groundwave (A), reflections from the bottom of the sand layer (B), wetting front (C), side of the tank (D), and the airwave (E) (Fig. 4). Changes in the GPR arrivals during the experiment are shown for four representative times in the multi-offset images in Fig. 5 and four representative antenna offsets in the constant offset images in Fig. 6. Note that no processing other than dewow filtering and time-zero correction has been performed on these data, and plots were made without gaining the data. We focus our analysis on the bottom of sand reflection (B) for inferring average water contents in the tank and the wetting front reflection (C) for monitoring the advance of the front during infiltration.

The reflection produced by the bottom of the sand layer (B) can be clearly identified during the majority of the experiment, but it is obscured during the infiltration period as the wetting front migrates downward and intersects it (Figs. 5 and 6). A hyperbolic moveout of wave traveltime with antenna offset consistent with Eq. (1) can be seen in the multioffset data at most times, though interference with other arrivals is apparent in Fig. 5b and c. For the constant offset images in Fig. 6, the reflection patterns observed through time are similar to those observed for the moisture probe data, though are inverted due to the inverse relationship between water content and wave velocity.

Reflection $\mathrm{C}$ is associated with the downward moving wetting front. The wetting front reflection is difficult to identify in the constant-offset data at early times $(8-10 \mathrm{~min})$ due to interference with the groundwave (i.e., arrival A in Fig. 6). At later times in the experiment $(15-20 \mathrm{~min})$, the wetting front arrival is still difficult to identify, though the cause of this problem is hard to determine directly from the data. $\mathrm{Nu}-$ merical modeling results indicate that reflections from the walls of the tank (indicated as arrival D in Figs. 5 and 6) contribute to interference obscuring the wetting front. The dry soil conditions ahead of the front could also allow for refracted waves to be produced, though such arrivals were not readily identified in the data. As the wetting front moves into the region of higher water content near the bottom of the tank, a loss of reflection amplitude is also expected due to the decreasing contrast in dielectric constant across the interface. Given that variations in the propagation of the wetting front were observed across the tank with the lateral arrays of moisture probes, lateral variability in the depth of the wetting front could decrease the coherency of reflection event $\mathrm{C}$ in the multi-offset data. We are not able to quantify the degree

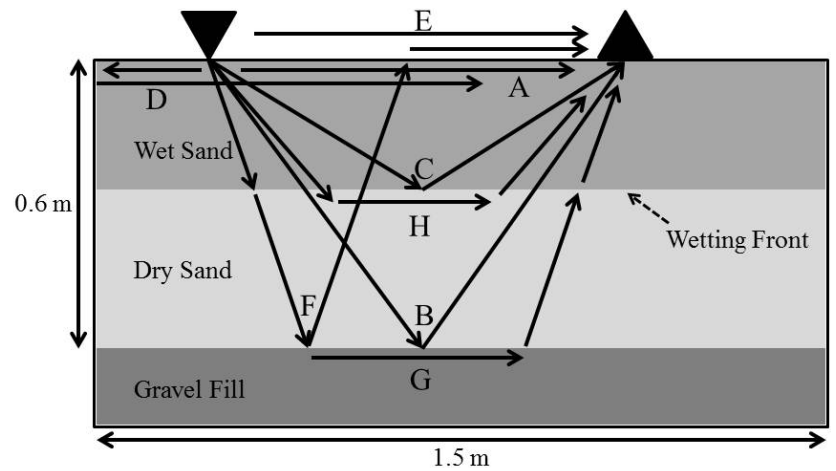

Fig. 4. Raypaths for selected arrivals discussed in the paper. Arrivals shown here include the groundwave (A), bottom of sand reflection (B), wetting front reflection (C), side of tank reflection (D), airwave $(\mathrm{E})$, air-refracted bottom of sand reflection $(\mathrm{F})$, refraction through the gravel layer $(\mathrm{G})$, and wetting front refraction $(\mathrm{H})$.

of lateral variability that occurred from the GPR data alone, however, given the single transmitter position used for the WARR survey in the experiment; in future experiments, the collection of intermittent constant offset profiles may help to directly identify such variability.

\subsection{NMO analysis of GPR arrivals}

\subsubsection{Bulk soil response}

The reflection traveltimes estimated for arrival B (bottom of the sand layer) can be used to infer variations of electromagnetic (EM) wave velocity and estimate the average water content of the tank over the course of the experiment. The reflection traveltimes picked from the multi-offset images were used with Eq. (1) to estimate the average (RMS) wave velocity within the tank throughout the duration of the experiment. The dielectric constant was then determined with Eq. (2), and water content values shown in Fig. 7 a were obtained using the Topp equation (Eq. 3).

Figure 7 a shows that the trend in the depth-averaged water content estimated from the probes and that determined from velocity analysis of reflection B are in reasonably good agreement. The GPR results generally underestimate the probe data by about 0.03 volumetric water content, with the maximum discrepancy remaining below 0.05 volumetric water content. In contrast, the NMO analysis of the synthetic GPR data shows a tendency to overestimate the average tank water content calculated from the simulated probe measurements (Fig. 7c), with discrepancies on the order of 0.01 volumetric water content but not exceeding 0.03 volumetric water content.

NMO analysis can also provide estimates for the depth to the interface causing the bottom of sand reflections, i.e., the thickness of the sand layer in the tank, which are shown in Fig. 7b. The average depth to the bottom of the sand layer estimated over the course of the experiment is $58.7 \mathrm{~cm}$, which 
a) Initial Conditions

a) Experiment Time $=1 \mathrm{~min}$

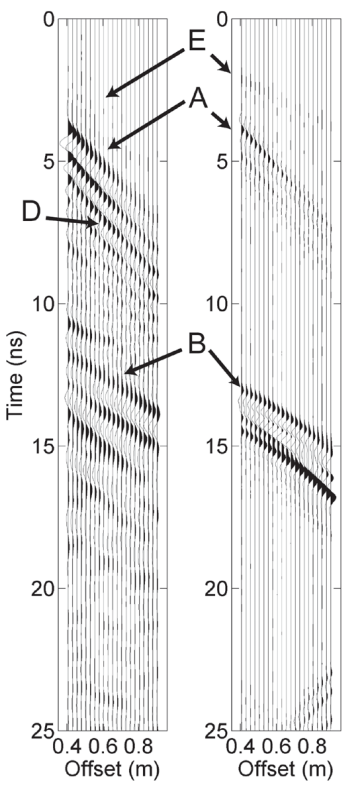

b) Infiltration Conditions

b) Experiment Time $=9 \mathrm{~min}$

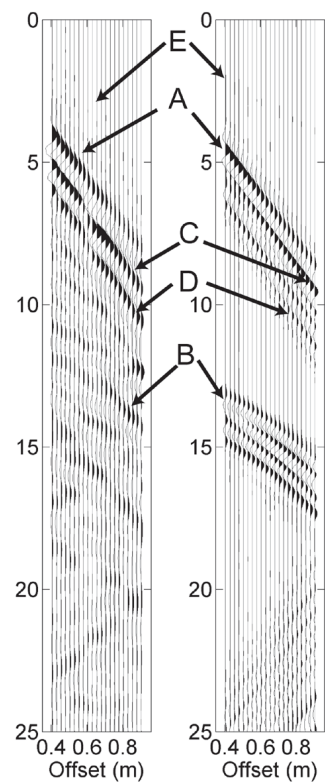

c)

Infiltration Conditions

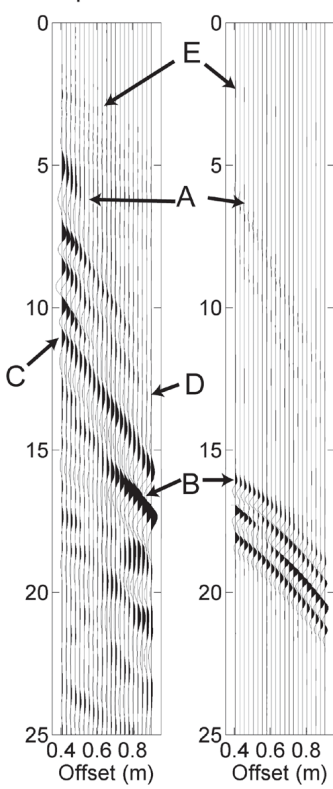

d) Recovery Conditions

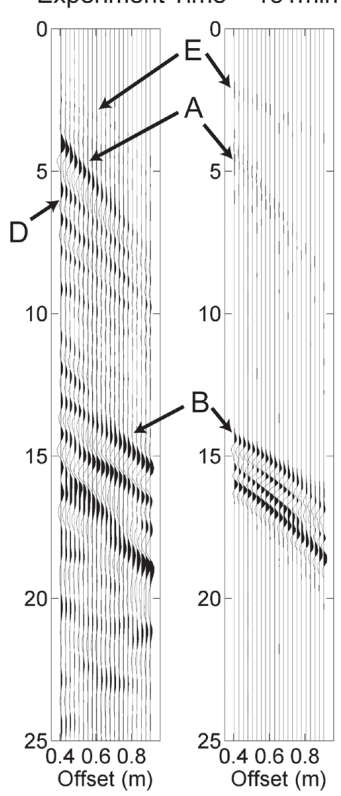

Fig. 5. Multi-offset GPR sections at 1, 9, 21, and $131 \mathrm{~min}$ into the experiment are shown to represent initial, infiltration, and recovery conditions, respectively. For each time, data from the lab experiment are shown on the left and simulated data are shown on the right. Visible arrivals include the groundwave (A), bottom of sand reflection (B), the wetting front reflection (C), side of tank reflection (D), and airwave (E).

is a $2 \%$ error relative to the true sand thickness of $60.0 \mathrm{~cm}$. During the infiltration period, however, errors ranged from an underestimate of the interface depth of $15 \mathrm{~cm}(25 \% \mathrm{er}-$ ror) to an overestimate of $5 \mathrm{~cm}$ ( $8 \%$ error). Although the errors are not as large for the analysis of the synthetic data (Fig. 7d), they still vary considerably $(\sim 6 \%)$, implying that even under optimal conditions it can be challenging to obtain accurate depth estimates from GPR during highly dynamic hydrologic events.

In both the laboratory and simulated experiments, there are a variety of interfering waves that could have affected our ability to accurately pick the traveltimes for reflection B. Several examples of these interferences are illustrated using the simulated wavefields given in Fig. 8. Waves reflected from the bottom of the tank and subsequently refracted in the air at the surface of the tank (F) and refracted through the unsaturated gravel at the base of the tank $(\mathrm{G})$ both reach the receiver before the sand reflection (B) in Fig. 8. At large offsets these waves arrive at the receiver antenna slightly before reflection $\mathrm{B}$, suggesting the potential for an interpretational bias causing the water content underestimation observed in Fig. 7a. The effect appears to be small or insignificant, however, given that the analysis of the simulated data over-predicted the water content. Reflections from the wetting front (C) and walls of the tank (D) also complicate the interpretation of the reflection from the bottom of the tank. Figure 8 shows that these reflections are likely to overlap with the reflection from the bottom of the sand layer (B) at some offsets during infiltration, which is a likely explanation for the larger errors in sand depth that occurred during the infiltration period in Fig. 7b. One additional possibility is that accumulation of water along the seepage face at the bottom of the tank could produce a reflection above the bottom of the sand interface that causes an apparent decrease in the traveltime of B. Though this effect is possible, we have not been able to clearly identify such a response in the experiment or simulations.

The interferences described above would be expected to affect both the observed and simulated results in a similar manner. The significantly larger magnitude of the discrepancies and systematic water content underestimation observed in the lab versus simulated results, however, suggest that other sources of error may also be significant. Heterogeneity of the sand could potentially lead to non-uniform distributions of water content that are not captured by the model, despite the fact that we attempted to pack the sand uniformly. This problem could be exaggerated by the fact that the probes measure water content at a point, whereas GPR averages over a larger volume of the tank and can produce water content estimates biased toward dryer values in non-uniform materials (e.g., Moysey and Knight, 2004). Increased heterogeneity would also enhance the overall scattering in the GPR data, making it difficult to identify arrivals, producing overall larger errors in traveltime estimates. Finally, our use of the Topp equation to estimate water contents rather than calibrating a petrophysical equation specifically for our soil could 

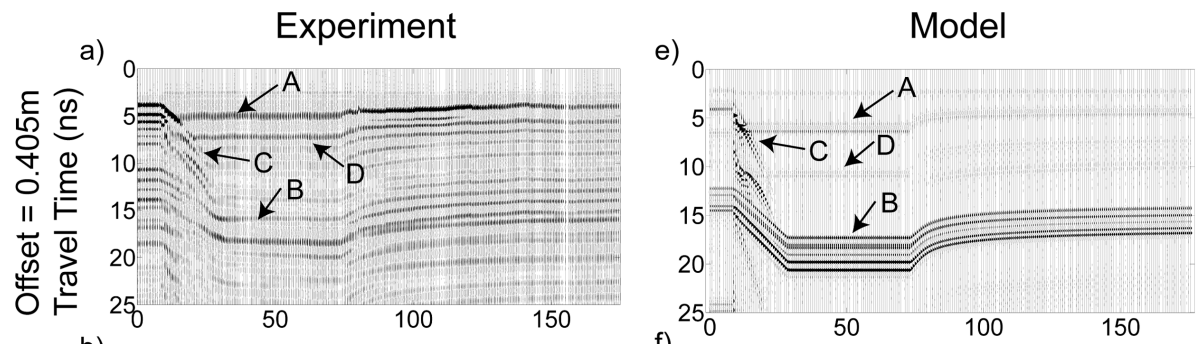

b) 0
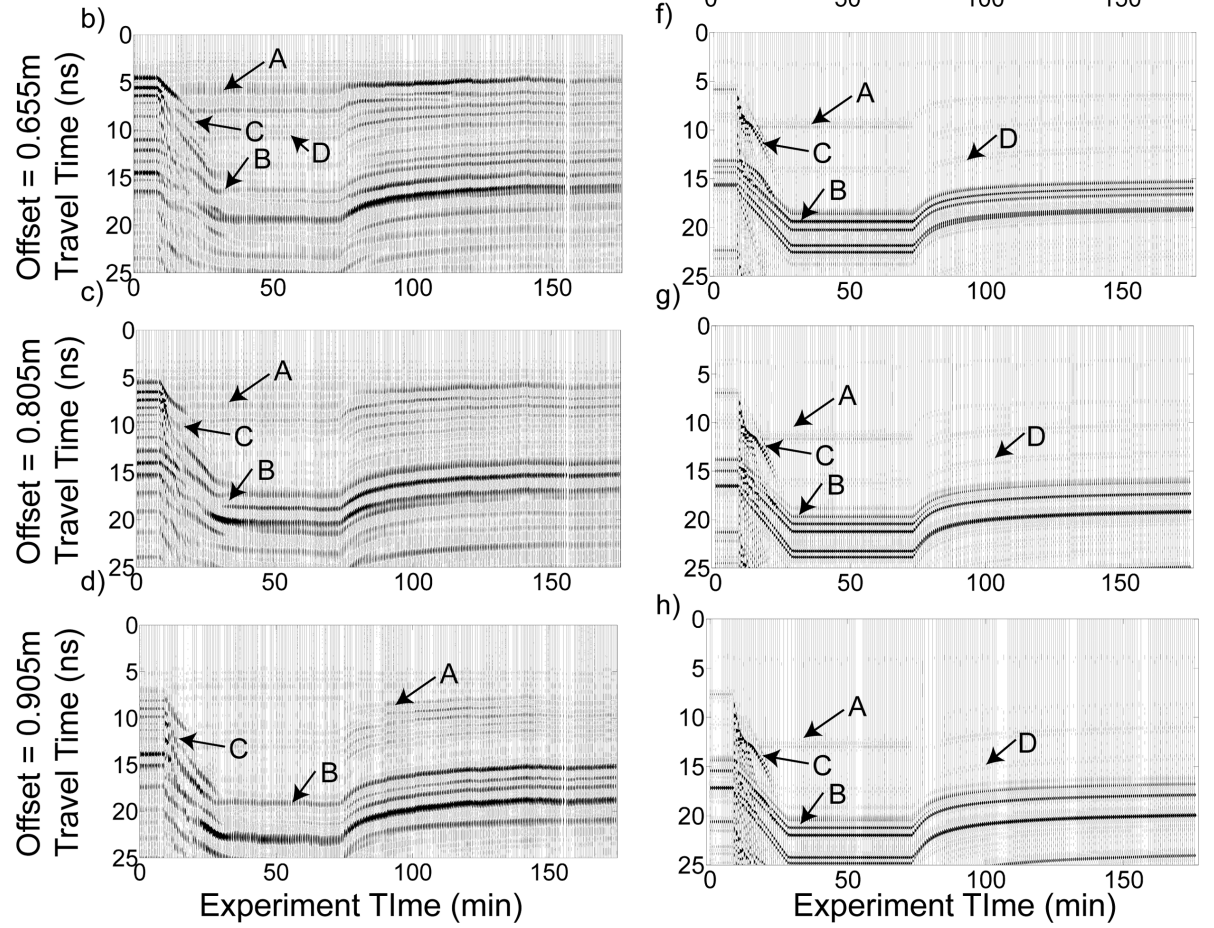

Fig. 6. Common offset projections for 4 of the 21 offsets of the experiment and model. Pointed out in the data are the groundwave (A), bottom of sand (sand-gravel interface) reflection (B), wetting front reflection (C), and side of tank reflection (D).

also account for some of the discrepancy we observe between the GPR and water content probe results.

\subsubsection{Wetting front migration}

Despite the challenges in identifying the wetting front reflection discussed earlier, it is possible to approximately track this arrival in the GPR data by simultaneously considering multi-offset gathers at fixed survey times and traveltime trajectories in common-offset gathers over the course of the experiment. We estimated the traveltimes for the wetting front reflection using a cross-correlation picking algorithm accompanied with manual adjustments to refine the estimate of first arrival time. The EM wave velocity estimated behind the wetting front by NMO analysis is relatively constant over time with a value of $0.08-0.1 \mathrm{~m} \mathrm{~ns}^{-1}$ in the wetted part of the tank. Applying the Topp equation, this range of velocity corresponds to $0.20-0.27$ volumetric water content, which is somewhat lower than the range of $0.26-0.34$ volumetric water content observed behind the wetting front with the moisture probes (Fig. 2a). In contrast, NMO analysis of the wetting front reflection in the synthetic GPR data produced water content estimates of $0.25-0.30$ volumetric water content, which are in agreement with the range $0.25-0.31$ volumetric water content simulated with HYDRUS-1D (Fig. 2b). Similarly, there is increasingly poor agreement between the depth of the wetting front inferred by GPR and the probes as the experiment progresses, whereas a relatively good agreement was found for the simulation. As a result, the apparent velocity of the wetting front found by analyzing the experimental GPR data is roughly half that inferred from the probe observations (Fig. 3a), whereas a good agreement of the front velocity was found in the analyses of the synthetic data (Fig. 3b).

Wave interference leading to interpretational errors is one of the most likely factors contributing to the discrepancies observed between the GPR and probe measurements. It is clear from the wavefield simulations in Fig. $8 \mathrm{~b}$ that there is significant potential for interference between the wetting front reflection (C), a reflection from the side of the tank (D), 
a)

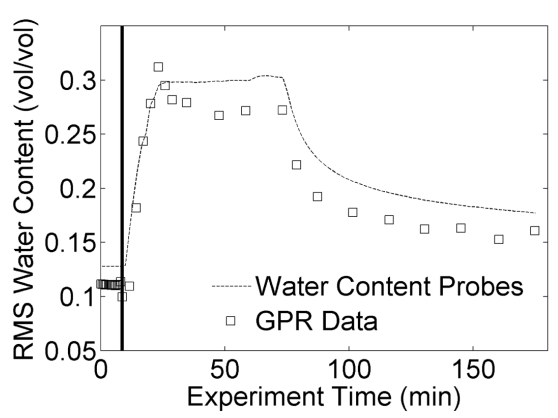

c)

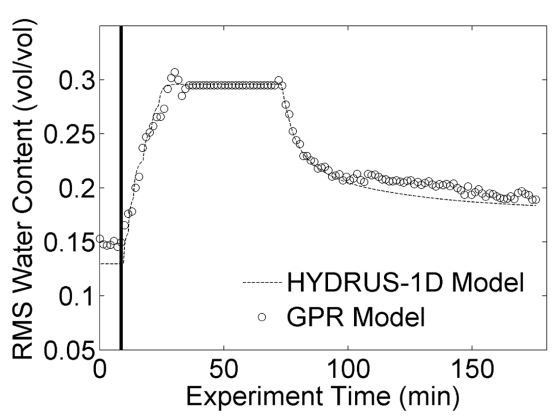

b)

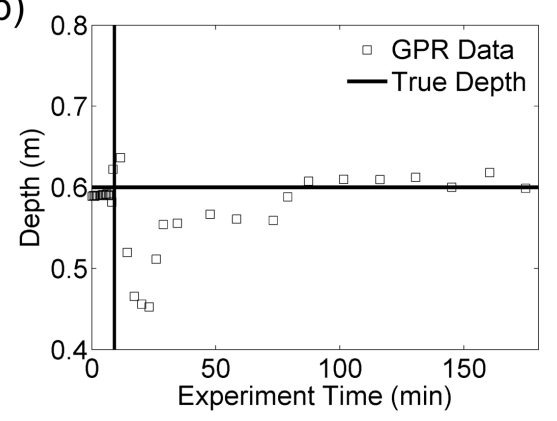

d)

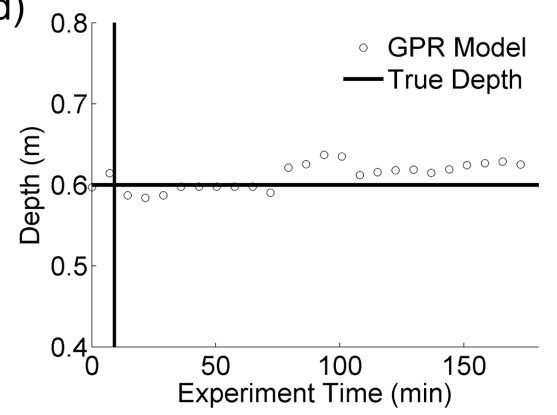

Fig. 7. (a, c) Average water content during the experiment estimated using the bottom of sand reflection in observed and simulated GPR data, moisture probes, and flow modeling with HYDRUS-1D. (b, d) Depth to reflector estimated from bottom of sand reflection for both GPR data and model. Vertical lines indicate the onset of irrigation.

and refractions associated with these features $(\mathrm{H})$ produced by waves traveling through the high velocity region ahead of the wetting front. For example, by assuming that the region behind the wetting front is uniform, a basic traveltime calculation indicates that $\mathrm{C}$ and $\mathrm{D}$ will arrive coincidently at the first receiver position, i.e., offset $=0.44 \mathrm{~m}$, when the wetting front is at $0.19 \mathrm{~m}$ depth and at the last receiver position, i.e., offset $=0.90 \mathrm{~m}$, when the wetting front is at $0.26 \mathrm{~m}$ depth. The arrival time of the wetting front reflection will therefore be underestimated because of the misidentification of arrival $\mathrm{D}$ for $\mathrm{C}$ for some (or eventually all) receivers when the wetting front migrates to depths beyond $0.19 \mathrm{~m}$. The magnitude of the traveltime error will increase as the wetting front propagates downward until such time as $\mathrm{C}$ and $\mathrm{D}$ can be identified as distinct arrivals. The simulations shown in Fig. 8b are representative of the point in the experiment when the wetting front has migrated about $30 \mathrm{~cm}$ to reach the midpoint of the tank. It is notable that this is also the time at which the greatest discrepancy occurs between the wetting front depth estimated by the simulated water contents and GPR in Fig. 3b. It is difficult to generalize this finding directly to the experimental data given that subtle differences from the simulations associated with the timing of the wetting front migration, diffuseness of and water content behind the wetting front, and specifics of the actual GPR wavelet in the experiment could all influence the observed response. Regardless, significant discrepancies in the estimated depth of the wetting front in the experimental data (Fig. 3a) also begin to occur when the front is located in the middle of the tank and increase as the wetting front propagates downward. This trend suggests that, at least in this experiment, accurate estimation of the traveltimes for the wetting front reflection are not trivial to obtain due to wave interferences.

Details associated with the specifics of the flow system in this experiment may also contribute to the discrepancies between the probe and GPR results in Fig. 3a. For example, the observed increase of water content with depth (Fig. 2a) suggests a loss of dielectric contrast as the wetting front migrates through the tank, therefore causing the loss of amplitude of the wetting front reflection (C) observed over time in Fig. 6. It becomes increasingly difficult to track the reflection and accurately estimate traveltimes as the experiment progresses, particularly for the noisy experimental data. It is also possible that the bias in Fig. 3a could be related to non-uniformity of the wetting front such that reflections produced by structural or water content heterogeneities at shallower depths in the tank are misinterpreted as the wetting front.

Overall, the analysis of the empirical data suggests that NMO analysis of time-lapse WARR data provides some qualitative insight about wetting front migration during an infiltration event. The results in the experiment, however, appear to fall short of providing accurate quantitative estimates of water content behind the front or of the position and velocity of the front. A significant factor contributing to these errors is wave interference caused by reflections from the walls of the tank. Such boundary reflections would not typically be 

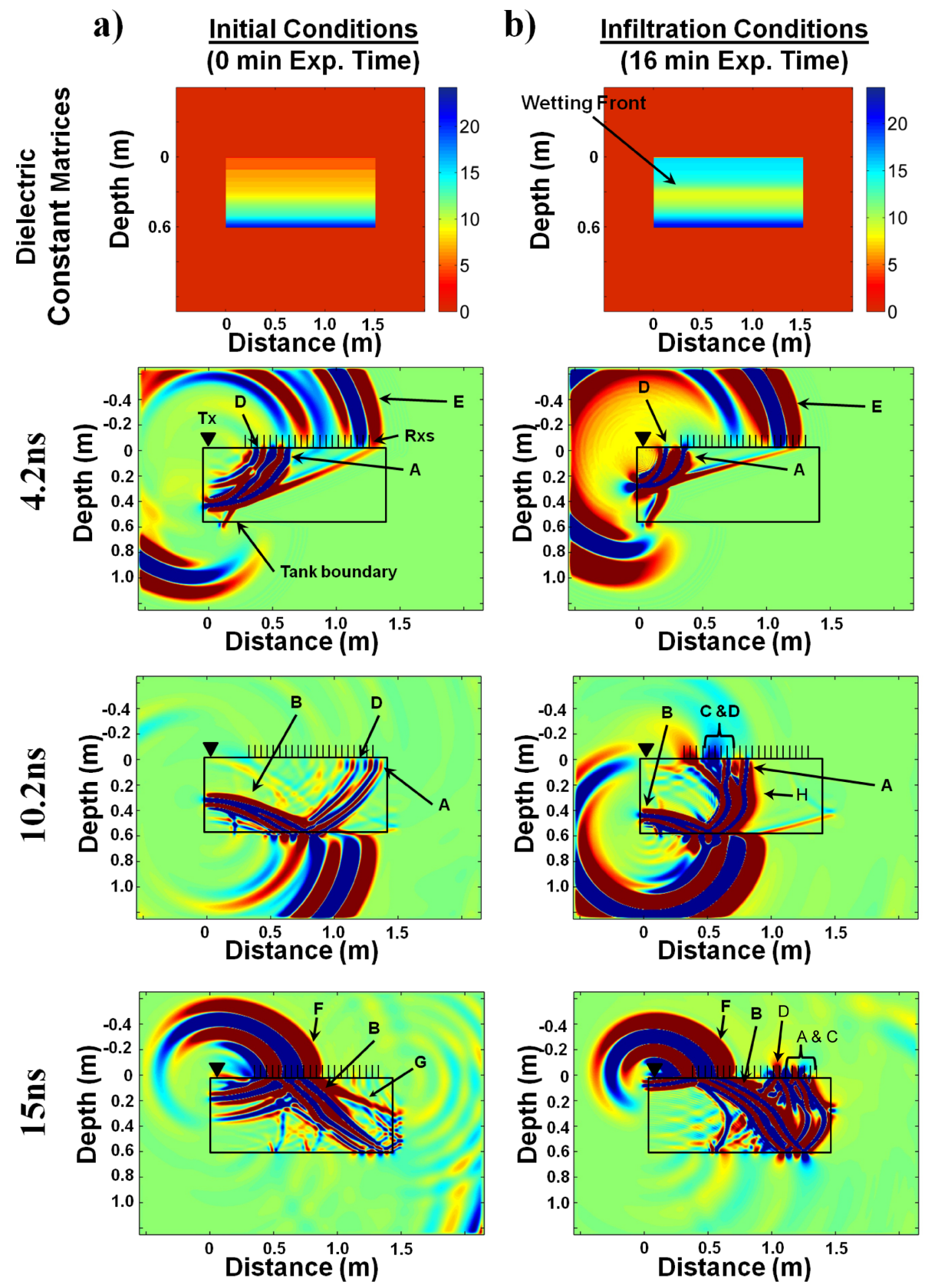

Fig. 8. Propagation of radar waves during iterations of the 2-D radar model showing evolution of radar wavefield through time. Visible arrivals are the groundwave (A), bottom of sand reflection (B), wetting front reflection (C), side of tank reflection (D), airwave (E), airrefracted bottom of tank reflection $(\mathrm{F})$, bottom of sand refraction $(\mathrm{G})$, and wetting front refraction $(\mathrm{H})$.

present in field settings, thereby making it easier to identify the wetting front, though other scattering could still cause considerable noise to obscure the arrival.

\subsection{Groundwave dispersion}

Although not used for the analysis in this study, we point out that the groundwave arrival (A) is also difficult to identify at early experiment times due to interference from other arrivals, e.g., the reflection from the wetting front. At later times the groundwave arrival is readily observed, but evidence of multiple reflections from the wetting front leading to dispersive behavior was seen in both the simulations and the data. This dispersive behavior occurs when the low velocity wetted zone has a thickness similar to the radar wavelength. This layer essentially traps the energy, causing interference between reflection multiples and dispersion of the groundwave (van der Kruk, 2006). This is most 
easily identified by a diagnostic shingling appearance in the groundwave arrival in multi-offset gathers (van der Kruk et al., 2009). For instance, the shape of the groundwave wavelet is clearly affected at larger offsets, suggesting that dispersion is a factor in the data. Preliminary results (not shown) also indicate velocity dependent shifts in the frequency spectra of the groundwave occur at early infiltration time $(8-10 \mathrm{~min})$ when the wetting front is very shallow, which is characteristic of dispersion due to the presence of a low-velocity waveguide (van der Kruk et al., 2009). We did not, however, observe the shingling effect in the multi-offset data suggested by van der Kruk et al. (2009) as a diagnostic indicator for dispersive waves caused by the presence of a low-velocity waveguide. This is likely because the longest offset in our data $(0.9 \mathrm{~m})$ is less than what is required to observe the shingling effect (van der Kruk, 2006). There is also a loss of amplitude for the groundwave at large offsets, and at all offsets the amplitude decreases during the period of irrigation, but rebounds slightly when the irrigation is terminated. While we have not evaluated the cause of these amplitude variations, they are consistent with attenuation occurring with changes in electrical conductivity associated with the varying water contents. Due to the potential for dispersion and amplitude effects for the groundwave, we chose not to analyze the groundwave arrival in this work as questions remain whether accurate wave velocities can be estimated from NMO analysis of the groundwave during infiltration events (van der Kruk et al., 2009).

\subsection{Applicability to heterogeneous systems}

Despite the fact that the NMO analysis used in this work was relatively simple, that our modeling assumption of a laterally uniform wetting front may be inaccurate based on the moisture probe data, and that there was substantial noise in the GPR data generated by scattering and refractions, we still obtained a good deal of quantitative insight into the macroscopic flow processes occurring in the tank using transient WARR surveys. It is possible that full 3-D GPR imaging, where both the transmitter and receiver antennas are moved, could capture more details related to local variations in flow, i.e., non-uniformity of the wetting front or other preferential flow processes. For example, Truss et al. (2007) were able to capture the interaction between the wetting front and a meter-scale structural feature (sand-filled hole) that channeled flow during an experiment in the Miami Oolite. Both the 3-D GPR monitoring studies by Truss et al. (2007) and Haarder et al. (2011) suggest, however, that directly capturing small-scale preferential flow features can be challenging. Haarder et al. (2011) were able to observe changes in reflection amplitudes that they interpreted to be caused by ponding associated with funnel flow, but they were not able to interpret individual small-scale preferential flow features directly from the GPR data. These authors concluded that GPR was useful for identifying patterns associated with large-scale flow processes, which have been observed by both Haarder et al. (2011) and Truss et al. (2007) to cause macroscopic changes in water content that produced shifts in the traveltime of reflections associated with soil heterogeneities. This is consistent with our results, where we have found that a reflection from a subsurface interface, i.e., the sand-gravel boundary at the bottom of the tank, could provide reliable estimates of average water content over time. The complexity of the GPR response associated with the wetting front, the potential for preferential flow at scales below the resolution of GPR, and the quantitative consistency of water content estimates observed over both wetting and drying events in this study suggest that soil reflectors, i.e., physical contrasts in subsurface materials, are a critically important tool for quantitatively monitoring infiltration events.

Given that our experiment was intentionally designed to represent a simple soil environment with a single interface, it remains an open question whether our degree of success in monitoring infiltration using the NMO approach could be achieved in more complicated environments. We acknowledge that acquiring more data, e.g., full-resolution 3-D GPR surveys with multiple antenna offsets, will always hold more potential for resolving the details of infiltration in the subsurface. The time required to perform these surveys, however, is still a limiting factor; for example, Truss et al. (2007) report that in their study $50 \mathrm{~min}$ was required to perform each constant offset survey over a $10 \mathrm{~m} \times 10 \mathrm{~m}$ area using a custom single channel GPR that was integrated with an advanced positioning system specifically for 3-D surveying. In contrast, multi-channel GPR systems amenable to fast WARR surveying over large areas are commercially available "offthe-shelf" at a reasonable cost. If NMO analysis of transient WARR data could be shown to provide reliable average water content estimates in heterogeneous soils, it would open a new opportunity to provide critically important data to hydrologists and soil scientists working at catchment scales.

\section{Conclusions}

A lab-scale infiltration and redistribution experiment was performed to evaluate whether multi-offset GPR could effectively constrain subsurface structures, track infiltration fronts, and monitor water content variability with time in a dynamically evolving system. The unique form of automated time-lapse multi-offset surveying used in this study allowed us to collect a 3-D GPR data cube that can be viewed as either multi-offset or constant offset gathers. Normal-moveout (NMO) analysis of reflections related to the bottom of a sand layer were used to independently estimate the mean radar velocity and average soil water content of the tank over the course of the experiment and provided agreement with averaged moisture probe measurements to within $0.03-0.05$ volumetric water content. It was also possible to independently determine the thickness of the sand layer in the tank with an 
average error of about $2 \%$ and maximum error on the order of $25 \%$, which occurred as the infiltrating wetting front approached this interface. The movement of the wetting front reflection was also visible in the GPR data, though it was difficult to track without interpreting the arrival as a reflection surface in the 3-D GPR data cube. NMO analysis of the wetting front reflection resulted in underestimates of water content in the wetted zone on the order of 0.06 volumetric water content compared to measurements made with the moisture probes. Likewise, the depth of the front was typically underestimated leading to underestimation of the wetting front velocity by a factor of 2 .

Analysis of data for a set of numerical experiments conducted in parallel showed a much better agreement between the GPR and moisture probes, particularly for the wetting front results. From the simulations, it was possible to infer that wave interference between the direct wave, multiple reflections from the wetting front, reflections from the side walls of the tank, and refractions associated with fast zones in the air above the tank, the dry sand below the wetting front, and the gravel lining the bottom of the tank could all contribute to noise in the data and errors in traveltime estimation. In particular, misidentification of refracted waves could potentially lead to overestimation of GPR velocity and underestimation of water content qualitatively consistent with discrepancies observed in the experiment. The magnitude of the discrepancies between GPR and moisture probe results for the simulations, however, is substantially smaller than that for the experiments. Other factors, such as an incorrect conceptualization of the tank as a homogeneous, onedimensional flow system, could play an additional role in accounting for the magnitude of the discrepancies between GPR and probe measurements.

The collection of 3-D GPR data would help to evaluate the significance of non-uniform flow versus other possible errors, such as inaccuracies in the petrophysical relationship used to estimate water content from dielectric constant. There is also significant potential for learning about the early-time behavior of the wetting front by analyzing changes in the shape of the groundwave wavelet caused by interference between arrivals, such as reflection multiples within the wetted zone. Tools such as dispersion analysis (van der Kruk, 2006) and full-waveform inversion (e.g., Busch et al., 2010; Minet et al., 2010) are particularly promising for this purpose.

This study illustrates the potential of transient multi-offset reflection surveys for improving the characterization of vadose zone dynamics, particularly the bulk response of a soil. The key advantage of the approach is that it is possible to estimate wave velocity and constrain the depth of subsurface structures directly from the GPR data without the need for supporting data, such as boreholes, to independently constrain the depth to reflectors. Changes in water content can then be obtained if a petrophysical relationship between dielectric constant and water content can be estimated for the soil. Given that multi-offset data can be collected quickly in the field using commercially available equipment, our results suggest that there is significant opportunity for noninvasive monitoring of soil moisture dynamics over catchment scales at time scales relevant to individual hydrologic events if strong radar reflectors exist within the soil profile. Improved characterization of the hydrologic state of the subsurface at catchment scales will ultimately lead to a better understanding of vadose zone processes and advances in largescale soil infiltration models.

Acknowledgements. This material is based upon work supported by, or in part by, the US Army Research Laboratory and the US Army Research Office under grant number W911NF-08-10370 and W911NF-10-1-0292. We thank two anonymous reviewers for their helpful comments that improved the manuscript.

Edited by: K. Roth

\section{References}

Berard, B. A. and Maillol, J.-M.: Multi-offset ground penetrating radar data for improved imaging in areas of lateral complexity - Application at a Native American site, J. Appl. Geophys., 62, 167-177, 2007.

Bradford, J. H.: Measuring water content heterogeneity using multifold GPR with reflection tomography, Vadose Zone J., 7, 184193, 2008.

Brewster, M. L., Annan, A. P., Greenhouse, J. P., Kueper, B. H., Olhoeft, G. R., Redman, J. D., and Sander, K. A.: Observed migration of a controlled DNAPL release by geophysical methods, Ground Water, 33, 977-987, 1995.

Busch, S., van der Kruk, J., Bikowski, J., and Vereecken, H.: Fullwaveform inversion of muti-offset surface GPR data, in: Proceedings of the 13th International Conference on Ground Penetrating Radar, Lecce, Italy, 21-25 June 2010.

Degacon.com, EC-5 Soil Moisture Sensor User Manual: http: //www.decagon.com/assets/Uploads/13876-01-Manual-EC-5. pdf, last access: August 2012.

Fisher, E., McMechan, G. A., and Annan, P.: Acquisition and processing of wide-aperture ground-penetrating radar data, Geophysics, 57, 495-504, 1992.

Freeland, R. S., Yoder, R. E., and Ammons, J. T.: Mapping shallow underground features that influence site-specific agricultural production, J. Appl. Geophys., 40, 19-27, 1998.

Freeland, R. S., Odhiambo, L. O., Tyner, J. S., Ammons, J. T., and Wright, W. C.: Nonintrusive mapping of near-surface preferential flow, Appl. Eng. Agr., 22, 315-319, 2006.

Grasmueck, M., Marchesini, P., Eberli, G. P., Zeller, M., and VanDam, R. L.: 4D tracking of water infiltration in fractured highporosity limestone, in: 2010 13th International Conference on Ground Penetrating Radar, Lecce, Italy, 21-25 June 2010, 1-6, 2010.

Greaves, R. J., Lesmes, D. P., Lee, J. M., and Toksoz, M. N.: Velocity variations and water content estimated from multi-offset ground-penetrating radar, Geophysics, 61, 683-695, 1996. 
Grote, K., Hubbard, S., Harvey, J., and Rubin, Y.: Evaluation of infiltration in layered pavements using surface GPR reflection techniques, J. Appl. Geophys., 57, 129-153, 2005.

Haarder, E. B., Looms, M. C., Jensen, K. H., and Nielsen, L.: Visualizing unsaturated flow phenomena using high-resolution reflection ground penetrating radar, Vadose Zone J., 10, 84-97, 2011.

Huisman, J. A., Sperl, C., Bouten, W., and Verstraten, J. M.: Soil water content measurements at different scales: accuracy of time domain reflectometry and ground-penetrating radar, J. Hydrol., 245, 48-58, 2001.

Huisman, J. A., Hubbard, S. S., Redman, J. D., and Annan, A. P.: Measuring soil water content with ground penetrating radar, Vadose Zone J., 2, 476-491, 2003.

Irving, J. and Knight, R.: Numerical modeling of groundpenetrating radar in 2-D using MATLAB, Comput. Geosci., 32, 1274-1258, 2006.

Jol, H. M., Annan, P., Arcone, S. A., Bridge, J., Bristow, C., Butnor, J., Buynevich, I. V., Cassidy, N., Comas, X., Damiata, B., Daniels, D., Doolittle, J., FitzGerald, D., Goodman, D., Higashi, N., Hongo, H., Jol, H., Koppenjan, S., Nishimura, Y., Piro, S., Redman, D., Saarenketo, T., Schneider, K., Slater, L., Steinberg, J., Yarovoy, A.: Ground Penetrating Radar: Theory and Applications, 1st Edn., edited by: Jol, H. M., Elsevier, Oxford, UK, 2009.

Lambot, S., Binley, A., Slob, E., and Hubbard, S.: Groundpenetrating radar in Hydrogeophysics, Vadose Zone J., 7, 137$139,2008$.

Lunt, I. A., Hubbard, S. S., and Rubin, Y.: Soil moisture content estimation using ground-penetrating radar reflection data, J. Hydrol., 307, 254-269, 2005.

Minet, J., Lambot, S., Slob, E. C., and Vanclooster, M.: Soil surface water content estimation by full-waveform inversion in the presence of thin layers, IEEE T. Geosci. Remote, 48, 1138-1150, 2010.

Moysey, S.: Hydrologic trajectories in transient ground-penetrating radar reflection data, Geophysics, 75, 211-219, 2010.

Moysey, S. and Knight, R. J.: Modeling the field-scale relationship between dielectric constant and water content in heterogeneous systems, Water Resour. Res., 40, W03510, doi:10.1029/2003WR002589, 2004.
Mualem, Y.: A new model for predicting the hydraulic conductivity of unsaturated porous media, Water Resour. Res, 12, 513-522, 1976.

Saintenoy, A., Schneider, S., and Tucholka, P.: Evaluating groundpenetrating radar use for water infiltration monitoring, Vadose Zone J., 7, 208-214, 2008.

Simunek, J., van Genuchten, M. Th., and Sejna, M.: HYDRUS 1D Code for simulating the one-dimensional movement of water, heat, and multiple solutes in variably saturated porous media, Department of Environmental Sciences and University of California Riverside, US Salinity Laboratory, USDA, ARS, Riverside, CA, 2005

Steelman, C. M. and Endres, A. L.: An examination of direct ground wave soil moisture monitoring over an annual cycle of soil conditions, Water Resour. Res., 46, W11533, doi:10.1029/2009WR008815, 2010.

Topp, G. C., Davis, J. L., and Annan, A. P.: Electromagnetic determination of soil water content: measurements in coaxial transmission lines, Water Resour. Res., 16, 574-582, 1980.

Truss, S., Grasmueck, M., Vega, S., and Viggiano, D. A.: Imaging rainfall drainage within the Miami oolitic limestone using high-resolution time-lapse ground-penetrating radar, Water Resour. Res., 43, W03405, doi:10.1029/2005WR004395, 2007.

van der Kruk, J.: Properties of surface waveguides derived from inversion of fundamental and higher mode dispersive GPR data, IEEE T. Geosci. Remote, 44, 2908-2915, 2006.

van der Kruk, J., Vereecken, H., and Jacob, R. W.: Identifying dispersive GPR signals and inverting for surface wave-guide properties, Leading Edge, 28, 936-940, 2009.

van Genuchten, M. Th.: A closed-form equation for predicting the hydraulic conductivity of unsaturated soils, Soil Sci. Soc. Am. J., 44, 892-898, 1980.

van Overmeeren, R. A., Sariowan, S. V., and Gehrels, J. C.: Ground penetrating radar for determining volumetric soil water content; Results of comparative measurements at two test sites, J. Hydrol., 197, 316-338, 1997.

Yilmaz, O.: Seismic Data Analysis: Processing, Inversion, and Interpretation of Seismic Data, in: Investigations in Geophysics, 2nd Edn., Volume I \& 2, edited by: Doherty, S. M. and Cooper, M. R., Society of Exploration Geophysicists, Tulsa, OK, USA, 1987. 